\title{
UCLA
}

Recent Work

Title

On Leasing, Borrowing and Financial Risk

Permalink

https://escholarship.org/uc/item/5mr7g75s

Authors

Levy, Haim

Sarnat, Marchall

Publication Date

1979-08-01 


\author{
Study Center in Managerial Economics \& Finance \\ Working Paper \\ On Leasing, Borrowing and Financlal Risk \\ $20-79$ \\ Hain Levy* and Marshall Sarnat** \\ August 1979
}

* Professor of Finance, The Hebrew University, Jerusalem; and Visiting Professor, University of Pennsylvania

** Professor of Finance, The Hebrew University, Jersualem; and Visiting Professor, University of California at Los Angeles.

The authors acknowledge the helpful comments of $T$. Ophir and 2. Lerman. 
Introduction

Much ink and even some Invective have been spilled in the debate over the merits of long-term financial lease contracts. But in sharp contrast to some of the more polemical discussions that have accompanied the development of modern financial theory, the frank exchange of views engendered by the problem of evaluating financial leases has not been a sterile exercise in product differentiation. A direct and important result of the debate has been a clarification of far-reaching importance of the principles which underlie the valuation of financing alternatives in a world of uncertainty. The relevant literature is voluminous. See, for example, Bower [1] Gordon [2], Lewellen et al. [4], and Myers et al. [6]. One important, and perhaps the most important, result of the debate has been the identification of the central (and often overlooked) problem of lease evaluation, that is, the need to neutralize financial risk in the evaluation of lease and other financial alternatives. The crucial importance of neutralizing the risk differential stems directly from the lease evaluation equation presented in Myers, Dill, and Bautista [6]. Using this equation, we present, in this paper, a relatively simple and straightforward, and therefore operational, solution to the practical problem of neutralizing the risk differential induced by lease contracts. ${ }^{1}$ 
Defining the Cash Flow

Although the valuation of the desirability of a leasing arrangement appears, on the surface at least, to be straightforward and perhaps even simple, nothing could be further from the truth. The frustration felt by many financial specialists when confronted with the received doctrine of leasing has been expressed recently by Myron Gordon:

"At various times over the last twenty years I have presented classes in finance with cases involving the choice between buying or leasing in acquiring a capital asset, and invariably I have been unhappy with the solutions proposed in the solution manuals and literature as well as the ones presented by the student," [2, p. 245]. Some of the difficulty in evaluating a lease proposal reflects an underlying ambiguity regarding the relevant alternative that should be used as the benchmark for comparison with the lease. Should the lease be compared with buying or with borrowing? obviously, a lease or borrow" comparison also implies a "lease or buy" comparison, so to avoid possible confusion we shall denote by "lease or buy" the comparison with a purchase that is financed by the firm's standard debt-equity mix.

On the surface, it would appear that the choice between the two alternatives -- lease or buy --is relatively simple. Assuming that both options have positive net present values, it might be argued that the firm should follow the alternative with the higher NPV. If the net present value of the lease, NPV (L), is greater than the net present value of the purchase option, NPV(P), the machine should be leased (and conversely in the case in which NPV(P) exceeds NPV(L)). But despite the apparent plausibility of this approach it can 
on a bond, constitute a fixed charge and therefore should be discounted using the interest rate, r. ${ }^{2}$ Thus the net present value of the lease, NPV $(L)$, is given by,

$$
N P V(L)=\sum_{t=1}^{n} \frac{(1-T)\left(S_{t}-C_{t}\right)}{\left(1+k_{T}\right)^{t}}-\sum_{t=1}^{n} \frac{(1-T) L_{t}}{(1+r)^{t}} .
$$

Purchase Cash Flow

Suppose now that the firm decides to buy rather than lease the machine. Assuming a purchase price of I dollars, and an annual depreciation expense of $D_{t}$, the relevant cash flow of the purchase option in year $t$ is given by

$$
(1-T)\left(S_{t}-C_{t}-M_{t}-D_{t}\right)+D_{t} \text {. }
$$

We first subtract the depreciation expense, $D_{t}$, in order to calculate the corporate tax liability, but then add it back because depreciation is not a cash outflow. We also deduct $\dot{M}_{t}$, which denotes any additional maintenance, insurance, or other costs engendered by the decision to buy rather than lease the machine. However, with no loss of generality we shall assume, for simplicity, that the sum of all such costs is zero. Hence the net cash flow of the purchase option in year $t$ reduces to

$$
(1-T)\left(S_{t}-C_{t}\right)+T D_{t}
$$

The net present value of the purchase option, $\operatorname{NPV}(P)$, is given by the formula,

$$
\operatorname{NPV}(P)=\sum_{t=1}^{n} \frac{(1-T)\left(S_{t}-C_{t}\right)}{\left(1+k_{\tau}\right)^{t}}+\sum \frac{T D_{t}}{\left(1+r_{1}\right)^{t}}+\frac{S_{n}^{\prime}}{\left(1+r_{2}\right)^{n}}-I
$$




\section{Comparing Alternatives}

The differential cash flow which is engendered by the decision to buy can now be derived by subtracting the annual lease cash flow from the annual buy cash flow:

$$
C F(P)-C F(L)=(1-T) L_{t}+T D_{t}
$$

where $C F(P)$ and $C F(L)$ denote the cash flow of the purchase and lease options, respectively. The lease commits the firm to a series of annual fixed after-tax rentals, (I-T) $I_{t}$, the purchase option of course involves an initial investment outlay of I but adds with certainty the annual tax shield from depreciation, $\mathrm{TD}_{t}$. Before we can make a meaningful comparison of the two alternatives, we must first neutralize any additional financial risk inherent in the lease i.e., we must hold the risk constant when comparing the two alternatives.

Thus, the fundamental difficulty in comparing the buy or lease alternatives relates to risk. Only if the risk incurred in both of these alternatives is identical can the difference in net present values be used as a guide to action:

$$
\operatorname{NPV}(P)-\operatorname{NPV}(L)=\sum_{t=1}^{\mathrm{T}_{1}} \frac{T_{t}}{(1+r)} t+\sum_{t=1}^{n} \frac{(1-T) L_{t}}{(1+r)^{t}}-I .
$$

In such a case, a positive differential indicates that the purchase option is preferable, and, conversely, a negative result indicates a preference for the lease. Equivalently, the critical maximum lease payment, $I_{t}^{*}$, which leaves the firm indifferent between the two alternative methods of acquiring the services of the asset can be derived from the following formula:

$$
\sum_{t=1}^{n} \frac{T D_{t}+(I-T) L_{t}^{*}}{(1+r)^{t}}=I .
$$


A fully equivalent and a more readily applicable formulation sets out the critical risk-equating payment stream on the loan in terms of principal repayment and the after-tax interest payment (i.e., $\left.(1-T) R_{t}\right)$ :

$$
\left(T D_{t}+(1-T) L_{t}\right)
$$

The equivalence of the pre-tax and post-tax formulations of the loan payments stream can be easily demonstrated. Denoting by $B_{t}$ the balance of the loan outstanding at the end of period $t$, the amount of principal repaid in period $t$ is equal to $B_{t-1}-B_{t}$. Hence, the after-tax payment stream (10) can be rewritten as

$$
T D_{t}+(1-T) L_{t}=\left(B_{t-1}-B_{t}\right)+(1-T) r B_{t-1}
$$

where $r$ denotes the interest rate. Recalling that by definition

$$
\begin{aligned}
R_{t}=I B_{t-1} & \text { we obtain } \\
& \quad T D_{t}+(1-T) L_{t}=\left(B_{t-1}-B_{t}\right)+(1-T) R_{t}
\end{aligned}
$$

which reduces to

$$
T D_{t}+(1-T) L_{t}+T R_{t}=\left(B_{t-1}-B_{t}\right)+R_{t} .
$$

Thus the pre-tax and after-tax formulations (9) and (10) can be used interchangcably to equalize the risk of the lease and purchese options. 3 The former is set out in terms of the interest actually received by the bank (creditor), and therefore constitutes a pre-tax payment from the firm's viewpoint; the latter formulation incorporates the firm's after tax interest payment, (I-T) R. Since the post-tax formulation is somewhat easier to apply, Equation (14) Is used to calculate the critical loan payment schedules in the numerical examples which follow (See Exhibit 1).

If the risk-neutralizing payments stream (appropriately defined) permits us to borrow an amount of money that exceeds the purchase price of the equipment, I, the equipment should be purchased rather than leased. In this Instance the firm can finance the purchase out of the proceeds from the loan and still have some money left over.

A practical, but fully equivalent, way to reach the optimal solution is to find the critical lease payment that leaves the firm lodifferent between the lease 
payments are less than $L^{*}$, the machine should be leased; for lease payments greater than $L^{*}$, the purchase option is preferable.

Solving Equation (14) explicitly for $L^{*}$ we obtain,

$$
L^{\star}=\frac{I-\sum_{t=1}^{n} T D_{t} /(1+(1-T) r)^{t}}{\sum_{t=1}^{n}(1-T) /(1+(1-T) r)^{t}} .
$$

Using the data of our hypothetical numerical example and the SYD depreciation assumption, the critical annual lease payment, $I^{*}$, is equal to $\$ 1,517.50$

Before going on to a demonstration that for an annual lease payment of $\$ 1,517.50$ the firm will indeed be indifferent between the lease and buy alternatives, let us first verify that the computational procedure has actually equated the riskiness of the two financing strategies. (The neutralization process is shown for the first year only but the interested reader can verify the risk neutralization in all of the ten years under consideration by examining Exhibit 1.)

If the firm leases the machine the annual cash flow is given by

$$
\begin{aligned}
& (1-T)(S-C)-(1-T) L=(1-T)(S-C)-0.50 \times \$ 1,517.50= \\
& (1-T)(S-C)-\$ 758.75 .
\end{aligned}
$$

If the firm buys the machine, the first year's cash flow becomes

$$
\begin{aligned}
& (1-T)(S-C)+T_{1}=(1-T)(S-C)+0.50 \times \$ 1,818.30= \\
& (1-T)(S-C)+\$ 909.15 .
\end{aligned}
$$

$(\$ 1,818.30$ represents the first year's depreciation allowance using the SYD method (see Exhibit 1, Column 4.)

But, In addition, if the firm buys the machine, it must also make an initial outlay of $\$ 10,000$ (the purchase price of the machine). What is the size of the loan required to neutralize the leverage effect? Recalling our previous analysis, we can find the annual payments of interest and principal required to equalize the annual cash flows of both alternatives 
An alternative, but equivalent, procedure for analyzing the lease or buy alternatives may prove helpful. Since the firm incurs no initial outlay should it decide to lease, let us assume that it deposits I dollars of its own capital in the bank at a post-tax interest rate $(1-T)$. Each year the firm reduces its deposit by the amount $(1-T) I+T D_{t}$ and adds this amount to the annual cash flow of the lease. This procedure is similar to the one described in the text with one distinction. Instead of paying interest and principal, the firm simply incorporates this sum in the annual cash flow of the lease. Once again this results in identical cash flows for both the lease and buy options. If the firm has to deposit in the bank more than I in order to ensure a receipt in year $t$ of $(1-T) L+T D_{t}$, buying the machine is preferable. If a deposit of less than $I$ is sufficient, leasing is the better alternative. Now let us turn to Exhibit 1 and examine the logic of the case in which the firm will be indifferent between the two alternatives. Given the assumed annual lease payment of $\$ 1,517.50$, the firm will be indifferent between the lease and buy option if the required loan, $B$, is exactly equal to the initial 
buys the machine it will have an additional $\$ 1,000$ since the machine costs less than the loan required to equalize the riskiness of the two alternatives. Thus, in this instance buying is preferable to leasing. Conversely, if the lease payment is less than $\$ 1,517.50$, the annual charges on the loan required to equalize the cash flows will be less than that of Exhibit 1, so the firm must borrow less than $\$ 10,000$, say $\$ 9,000$, if the leverage is to be neutralized. This amcint is insufficient to purchase the machine, and an additional $\$ 1,000$ is required. Thus, in this case leasing is preferable to the purchase option.

In the preceding discussion the logic underlying the correct appraisal of a lease or buy. decision has been illustrated by numerical examples. Fortunately there is no need, in practice, to carry out all of the cumbersome arithmetic which was used to illustrate the problem. As we have already indicated, a direct solution to the lease or buy problem can be btained by solving for the critical value of $L^{*}$ [see Equation (15)] and comparing the critical value with the proposed lease payments. This confirms the numerical analysis given above which indicated that for a lease payment of $\$ 1,517.50$ the firm would be indifferent between the lease and buy options. For $L>\$ 1,517.50$ the firm should buy the machine, and for $L<\$ 1,512.50$ leasing is the better financing strategy. This is shown in Exhibit 2, which gives the results of calculations similar to those of Exhibit 1 for altemative levels of lease payments. As we have just noted, the firm is indifferent between the lease or buy option for a lease payment of $\$ 1,517.50$. For $L=\$ 1,000$, a loss of $\$ 1,998$ is incurred if the machine is bought rather than leased, and for $L=\$ 2,500$ a gain of $\$ 3,792$ results should the firm decide to buy rather than rent the machine. 
1. R.S. Bower, "Issues in Lease Financing," Financial Mangement (Winter 1973), PP. 25-34.

2. M.J. Gordon, "A General Solution to the Buy or Lease Decision," Journal of Finance (March 1974), pp. 245-250.

3. H. Levy and F.D. Arditti, "Valuation Leverage and the Cost of Capital in the Case of Depreciable Assets," Journal of Finance (June 1973), pp. 687-694.

4. W.G. Lewellen, M.S. Long, and J.J. McConnell, "Asset Leasing in Competitive Capital Markets," Journal of Finance (June 1976), pp. 787-798.

5. M.H. Miller and C.W. Upton, "Leasing, Buying, and the Cost of Capital Services," Journal of Finance (June 1976), pp. 761-786.

6. S.C. Myers, D.A. Dill, and A.J. Bautista, "Valuation of Financial Lease Contracts," Journal of Finance (June 1976), pp. 799-819. 
3. It has been noted that if the corporate $\operatorname{tax}$ rate ( $T$ ) is uncertain or systematically varies with the economy, or if income cannot alvays be found to exploit the tax shelter, risk is not neutralized $y$, the formula in the text, as there are different amounts of shelter flow in

$$
R_{t}-(1-T) L_{t}+T D_{t}+T R_{t}
$$

or equivalently

$$
R_{t}-\left(R_{t}+D_{t}\right) T+L_{t}-L_{t} T
$$

We are inderted to R.S. Bower for this comment.

4. Since it is not immediately obvious that Equations (13) and (14) yield. the the sare solutions for $L_{t}^{*}$, a formal proof of their equivalence is given in the Apperaix. 
Substituting the right hand side of Equation (A-4) for $B_{n-1}$ yields,

$$
B_{n-2}=\frac{L_{n-1}(1-T)+T D_{n-1}+T B_{n-2} r}{1+r}+\frac{L_{n}(1-T)+T D_{n}+T B_{n-1} r}{(1+r)^{2}}
$$

which simplifies to

$$
B_{n-2}=\sum_{t=n-1}^{n} \frac{L_{t}(1-T)+T D_{t}+T B_{t-1} r}{(1+r)^{t-(n-2)}} .
$$

Continuing this substitution procedure we finally obtain

$$
B_{0}=\sum_{t=1}^{n} \frac{L_{t}(1-T)+T D_{t}+T B_{t-1} r}{(1+r)^{t}} .
$$

To find the critical lease payment, $L_{t}^{*}$, which leaves the firm indifferent between the buy and lease options, we simply substitute $B_{0}=I$ and solve for $L_{t}^{*}$,

$$
I=\sum_{t=1}^{n} \frac{L_{t}^{*}(1-T)+T D_{t}+T B_{t-1} r}{(1+r)^{t}} .
$$

Recalling that $T B_{t-I} I$ is identical to $T R_{t}$, where $R_{t}$ is defined as the interest paid on the loan at the end of period $t$, Equation $(A-7)$ is clearly the same as Equation (13) of the text.

In order to show that Equation (13) is equivalent to Equation (14) let us write $(A-2)$ as follows:

$$
B_{t-1}(1+r)-T B_{t-1} r=L_{t}(1-T)+T D_{t}+B_{t} \text {. }
$$

Hence:

$$
B_{t-1}=\frac{L_{t}(1-T)+T D_{t}+B_{t}}{1+(1-T) r}
$$

Using the same substitution procedure as above, and recalling that $B_{n}=0$, the critical lease payment $L_{t}^{*}$ can be found from the following equation: 


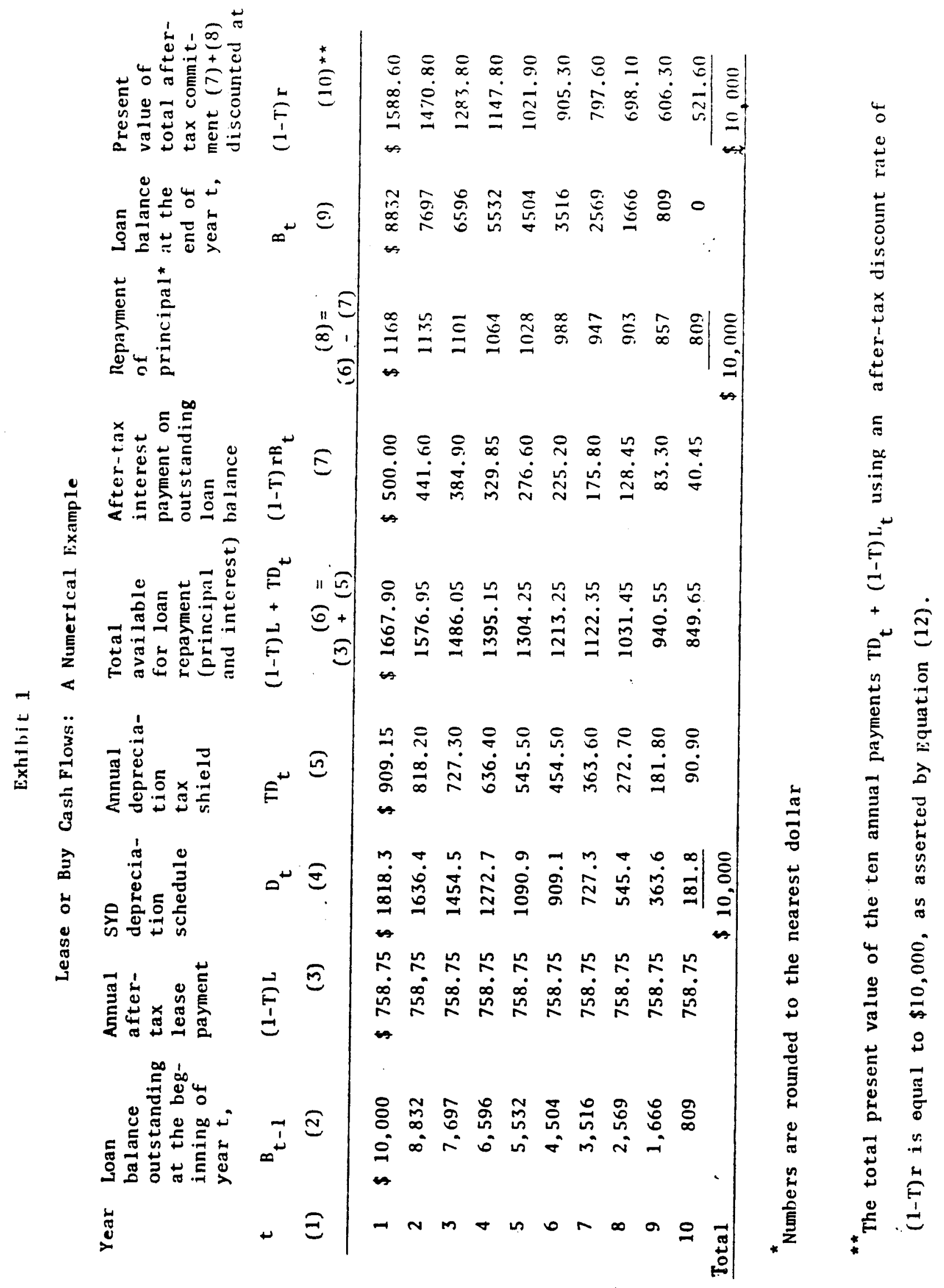

